\title{
Noninvasive Ventilation in Obese Subjects After Acute Respiratory Failure
}

\author{
Charlotte Bry MD, Sandrine Jaffré MD, Béatrice Guyomarc'h MSc, Frédéric Corne MD, \\ Sylvaine Chollet MD, Antoine Magnan MD PhD, and François-Xavier Blanc MD PhD
}

\begin{abstract}
INTRODUCTION: Noninvasive ventilation (NIV) has been widely used to treat acute respiratory failure in obese patients. Criteria that could help clinicians to decide whether they should continue to use NIV after such an initial episode remain unclear. Our retrospective study aims to analyze characteristics of subjects receiving long-term NIV after an initial hospitalization for acute respiratory failure. METHODS: From January 2011 to December 2012, 77 obese adults were admitted in the ICU of the respiratory disease department in Nantes University Hospital in France. After discharge, adherence, body mass index (BMI), and arterial blood gases were assessed or measured at 6 months and 12 months. RESULTS: In all, 53 subjects were analyzed, including $62 \%$ who were admitted for idiopathic acute hypercapnic respiratory failure. Mean BMI was $42 \pm 11 \mathrm{~kg} / \mathrm{m}^{2}$. Failure of NIV occurred in $10 \%$ cases in the ICU. At the end of the hospital stay, 34 subjects were discharged with NIV at home. They had higher BMI and higher initial inspiratory positive airway pressure than those who were not ventilated at home. During follow-up, $\mathrm{BMI}, \mathrm{P}_{\mathrm{aCO}_{2}}$, and bicarbonate rate significantly decreased. At 12 months, 4 subjects were not ventilated anymore after a mean duration of $6 \pm 4.2$ months of ventilation. Adherence was correct in $86 \%$, with a mean use of $7 \pm 3.1 \mathrm{~h} / \mathrm{d}$. Adherent subjects had better adherence at 1 month, a lower forced vital capacity, a higher bicarbonate rate, and a higher NIV breathing frequency when compared to subjects with poor adherence. CONCLUSIONS: Subjects with the most severe obesity or who experienced the most difficult initial ventilation were more likely to receive long-term NIV after initial management of acute respiratory failure in the ICU. In those subjects, long-term NIV at home was effective and well tolerated. Key words: adults; retrospective study; positive airway pressure; adherence; obesity; chronic respiratory disease. [Respir Care 2018;63(1):28-35. (C) 2018 Daedalus Enterprises]
\end{abstract}

\section{Introduction}

Obesity, defined as a body mass index (BMI) exceeding $30 \mathrm{~kg} / \mathrm{m}^{2}$, remains a serious public health problem, repre-

Drs Bry, Jaffré, Corne, and Chollet are affiliated with Service de pneumologie, l'institut du thorax, Centre Hospitalier Universitaire, Nantes, France. Ms Guyomarc'h is affiliated with Département Hospitalo-Universitaire 2020, médecine personnalisée des maladies chroniques, Nantes, France; INSERM, UMR1087, l'institut du thorax, Nantes, France; and CNRS, UMR 6291, Nantes, France. Drs Magnan and Blanc are affiliated with Service de pneumologie, l'institut du thorax, Centre Hospitalier Universitaire, Nantes, France; Université de Nantes, Nantes, France; Département Hospitalo-Universitaire 2020, médecine personnalisée des maladies chroniques, Nantes, France; INSERM, UMR1087, l'institut du thorax, Nantes, France; and CNRS, UMR 6291, Nantes, France.

The authors have disclosed no conflicts of interest. senting the fifth leading risk factor for death in the world. ${ }^{1}$ In France, obesity affects $15 \%$ of the population over 18 y of age. ${ }^{2}$ Respiratory diseases associated with obesity are mainly obstructive sleep apnea (OSA) and obesityhypoventilation syndrome. ${ }^{3,4}$

Noninvasive ventilation (NIV) is a central pillar of the treatment of respiratory failure in the obese, ${ }^{5}$ and its effectiveness has been demonstrated in both acute and longterm situations at subjects' homes. ${ }^{6-8}$ Obesity-hypoventilation syndrome has become the most frequent cause of

\footnotetext{
Correspondence: François-Xavier Blanc MD PhD, Service de Pneumologie, Hôpital G. et R Laënnec, Bd J Monod, 44093 Nantes cedex 1, France. E-mail: xavier.blanc@ chu-nantes.fr.
}

DOI: $10.4187 /$ respcare. 05302 
home ventilation before all other obstructive and restrictive respiratory diseases. ${ }^{9-11}$ However, criteria for initiating such ventilation after a stay in the ICU remain unclear.

In this study, we aimed to analyze characteristics of

\section{See the Related Editorial on Page 123}

obese subjects receiving long-term NIV after a hospitalization in a French ICU for acute respiratory failure (ARF) and to describe their outcomes over 1 year.

\section{Methods}

We conducted a descriptive, retrospective study in the ICU located in the respiratory disease department of the Nantes University Hospital in France.

\section{Population}

Subjects enrolled in this analysis were admitted to the ICU between January 1, 2011, and December 31, 2012, and had a BMI $>30 \mathrm{~kg} / \mathrm{m}^{2}$ at admission. Those who had surgery within the $24 \mathrm{~h}$ preceding admission in ICU were excluded. Subjects were first identified on the basis of the coding system, and then data were collected from original hospital files.

\section{Collected Data}

Demographic data included gender, age, smoking status, medical history, BMI, history of NIV, and history of hospitalization for ARF. Presence of OSA, already known or diagnosed later on, was also recorded. Pulmonary function testing was often performed at the end of the stay or during follow-up. When available, forced expiratory volume in one second $\left(\mathrm{FEV}_{1}\right)$, forced vital capacity (FVC), and total lung capacity (TLC) were recorded. Obstructive lung disease was defined as a ratio of $\mathrm{FEV}_{1}$ to $\mathrm{FVC}<0.70$. Restrictive lung disease was defined as a TLC $<80 \%$ of the predicted value. A mixed pattern of obstruction and restriction was defined as both $\mathrm{FEV}_{1} / \mathrm{FVC}$ ratio $<0.70$ and a TLC $<80 \%$ of the predicted value.

Data collected during hospital stay included cause of admission, ventilation modalities, duration of ventilation, arterial blood gases at entry and at discharge, and presence of cardiac failure. At discharge, the type of ventilator and mask, parameters of ventilation and associated oxygen therapy were recorded. If there was no ventilation at home when the subject was discharged, the reason was recorded.

Follow-up occurred 1 y after discharge, usually including consultations at 6 months and 12 months. BMI and arterial blood gases were recorded upon follow-up. Adherence was recorded by the health care supplier for NIV

\section{QUICK LOOK}

\section{Current knowledge}

Noninvasive ventilation (NIV) is largely used to treat respiratory failure in obese patients. The effectiveness has been demonstrated both in acute care and in longterm situations at patients' homes. However, criteria for following ventilation at home after a stay in the ICU remain unclear.

\section{What this paper contributes to our knowledge}

After acute respiratory failure in obese subjects, more than half received long-term NIV. These subjects had more severe obesity and more difficult initial ventilation. In those subjects, long-term NIV at home was effective and well tolerated. at home at 1, 6, and 12 months. Poor adherence was defined as a daily use of ventilation of $<4 \mathrm{~h} .{ }^{12}$ If ventilation was removed from a subject's home during follow-up, it was recorded and dated.

Additional hospitalizations for ARF in our university hospital, as well as death during the year after initial admission, were also recorded for all subjects.

\section{NIV Initiation in ICU}

Criteria used to initiate NIV during the ICU stay were signs and symptoms of ARF, significant hypoxemia, or respiratory acidosis. Specific NIV ventilators were used in the spontaneous/timed mode (Vision and V60, Respironics) with a face mask. Inspiratory positive airway pressure (IPAP) was initially set at $20 \mathrm{~cm} \mathrm{H}_{2} \mathrm{O}$ then modified in increments of $2-3 \mathrm{~cm} \mathrm{H}_{2} \mathrm{O}$ to obtain expiratory volumes of $450-500 \mathrm{~mL}$ and a reduction in $\mathrm{P}_{\mathrm{aCO}}$. Expiratory positive airway pressure was initially set at $5 \mathrm{~cm} \mathrm{H}_{2} \mathrm{O}$ and then modified in increments of $1-2 \mathrm{~cm} \mathrm{H}_{2} \mathrm{O}$, depending on the degree of hypoxemia or presence of apnea. $\mathrm{F}_{\mathrm{IO}_{2}}$ was set to obtain $\mathrm{S}_{\mathrm{pO}_{2}}$ of $88-92 \%$. The decision to intubate and initiate invasive ventilation was made when any of the following was observed: persistent hypoxemia, severe exhaustion, deteriorating consciousness, or hemodynamic failure. ${ }^{13,14}$

\section{NIV After Initial Management}

Once the initial episode resolved, some subjects continued NIV according to 2 modalities: NIV (Synchrony II S/T, Philips) or CPAP (Spirit S8 II, ResMed; PR 1 A-Flex, Philips). Indications for home NIV were persistent hypercapnia without acidosis despite initial NIV, recurrent hy- 
percapnia once initial NIV had been stopped for $24 \mathrm{~h}$, good adherence, and marked improvement with NIV. CPAP was chosen when OSA was strongly suspected (positive nocturnal oximetry) and hypercapnia was moderate $(<45 \mathrm{~mm} \mathrm{Hg}$ ). Should the subject not continue NIV, the reason was recorded (usually the subject's refusal or the absence of medical indication). After placement on NIV after the initial episode, subjects were transferred from ICU to a respiratory medicine general care ward to establish ventilation parameters according to results of arterial blood gases and nocturnal oximetry. Ventilation parameters were modified in increments of $1-2 \mathrm{~cm} \mathrm{H}_{2} \mathrm{O}$ to decrease nocturnal desaturations and $\mathrm{P}_{\mathrm{aCO}_{2}}$. Oxygen therapy was added in case of persistent nocturnal hypoxia, defined as $>20 \%$ of nighttime with $\mathrm{S}_{\mathrm{pO}_{2}}<90 \%$. Trained nurses provided education on appropriate use of the machine and the mask.

\section{Statistics}

Continuous data were presented as mean $( \pm \mathrm{SD})$ or median (minimum, maximum) based on the distribution. Categorical variables were presented as counts (proportions). The Mann-Whitney U test was performed to test for statistical differences in continuous parameters between 2 groups. The $\chi^{2}$ or the Fisher exact tests (based on expected frequency) were used to compare categorical variables between groups. Friedman and Wilcoxon tests were used to analyze the evolution between baseline and 1-y follow-up on BMI and arterial blood gases. All tests were 2-tailed. Data were analyzed using SPSS, version 19.0 (SPSS, Inc.; Chicago, Illinois) and SAS, version 9.3 (SAS, Cary, North Carolina). A $P$ value $<.05$ was considered statistically significant.

\section{Ethics}

The study was approved by the Institutional Review Board of the French-speaking society for respiratory medicine (Société de Pneumologie de Langue Française). Anonymized data have been used throughout the study, in accordance with the French data protection authority (Commission Nationale Informatique et Liberté).

\section{Results}

\section{Study Population and Ventilation in ICU}

A total of 77 obese patients were admitted during the study period in ICU; 24 were excluded because of thoracic surgery $<24 \mathrm{~h}$ prior to admission (usually corresponding to a scheduled procedure). Thus, 53 subjects were included in this study (Fig. 1). Baseline characteristics are displayed in Table 1. Main characteristics were mean age of $61 \pm 10 \mathrm{y}$,

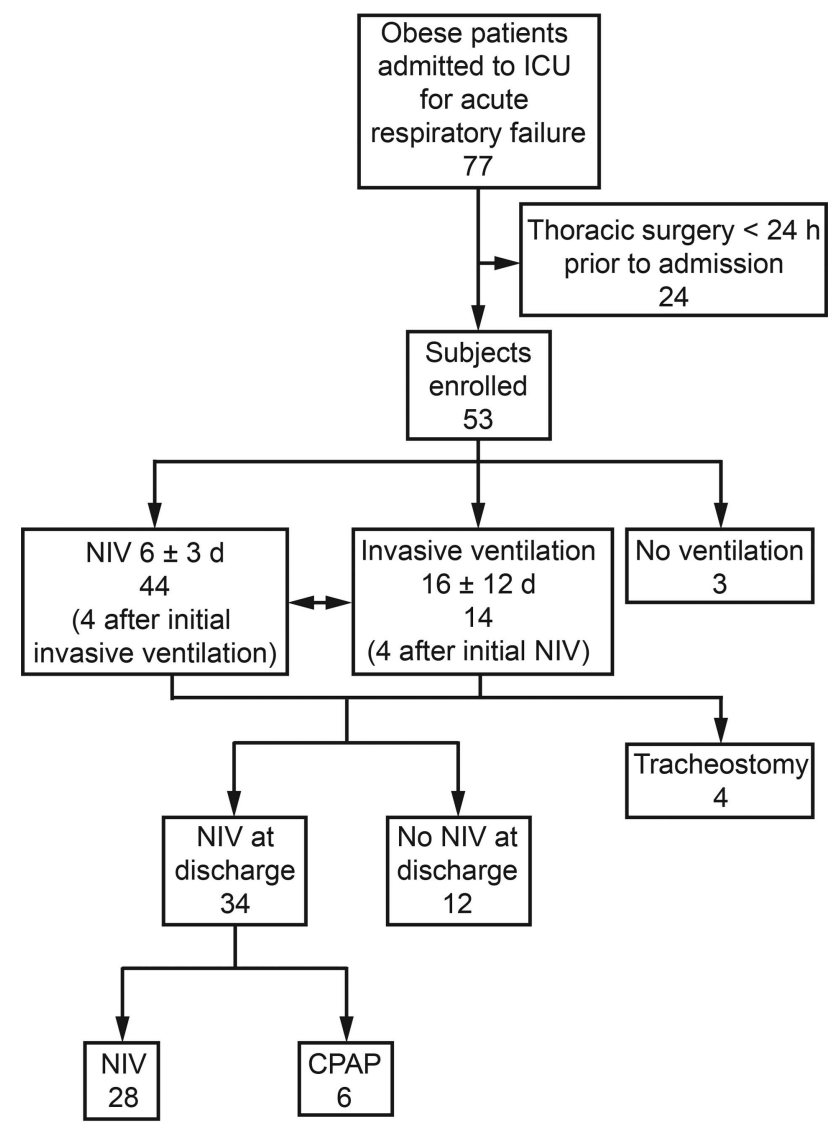

Fig. 1. Flow chart. NIV = noninvasive ventilation.

mean BMI $42 \pm 11 \mathrm{~kg} / \mathrm{m}^{2}, 60 \%$ of subjects had hypertension, $30 \%$ were current smokers, $70 \%$ had never been hospitalized for ARF, and $32 \%$ had been previously ventilated at home (half by CPAP for OSA). Among the 8 subjects previously ventilated by NIV, 5 were non-adherent and 2 stopped before inclusion. The remaining subject showed good adherence. Overall, 68\% of subjects had never been supported either with NIV or CPAP. An obstructive pattern was noticed in $41 \%$, a restrictive pattern in $16 \%$, and mixed pattern in $19 \%$.

Main causes of ARF were idiopathic acute hypercapnic respiratory failure (62\%), respiratory tract infections (32\%), acute pulmonary edema ( $28 \%$ ), and exacerbations of COPD (13\%) (Fig. 2). Measured data from arterial blood gases at admission are displayed in Table 1 . Notably, $66 \%$ of subjects had hypercapnic acidosis, and nearly $45 \%$ of subjects showed signs of congestive heart failure.

Of 44 subjects who received NIV during their hospital stay, 40 were ventilated with NIV at admission, while 4 received NIV after initial invasive ventilation. NIV failed in 4 subjects $(10 \%)$, leading to intubation and invasive mechanical ventilation. In addition, 10 subjects were intubated in the emergency department, and 3 did not receive any mode of ventilation (Fig. 1). 
Table 1. Baseline Characteristics of the Subjects

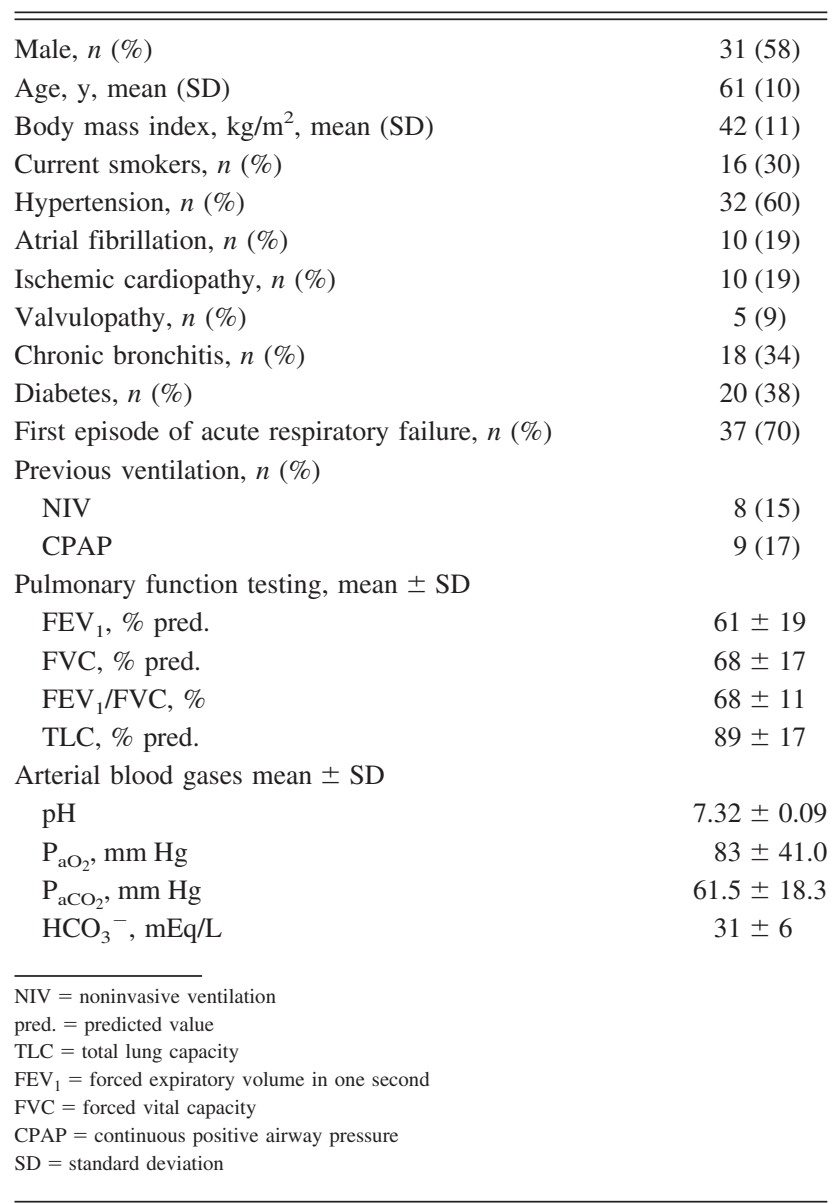

Parameters for NIV during the first $48 \mathrm{~h}$ were IPAP $22 \pm 2 \mathrm{~cm} \mathrm{H}_{2} \mathrm{O}$, expiratory positive airway pressure $7 \pm 2 \mathrm{~cm} \mathrm{H}_{2} \mathrm{O}$, NIV breathing frequency 16 breaths/min. Mean duration of invasive ventilation was $16 \pm 12 \mathrm{~d}$, compared to $6 \pm 3 \mathrm{~d}$ for NIV $(P=.01)$. Arterial blood gases at discharge were $\mathrm{pH} 7.42 \pm 0.4, \mathrm{P}_{\mathrm{aO}_{2}} 73.4 \pm 13.3 \mathrm{~mm} \mathrm{Hg}$, $\mathrm{P}_{\mathrm{aCO}_{2}} 42.6 \pm 7.5 \mathrm{~mm} \mathrm{Hg}$, and $\mathrm{HCO}_{3}-27 \pm 3 \mathrm{mEq} / \mathrm{L}$.

\section{Mode of Ventilation at Discharge From ICU}

Thirty-four subjects (64\% of the initial population) were ventilated with NIV at discharge, including 50\% who were not ventilated prior to admission, while 19 subjects did not receive NIV at discharge for the following reasons: 3 did not receive any ventilation during their hospital stay, 4 refused long-term ventilation, 4 were tracheostomized, and 8 did not have any indication for long-term ventilation.

Overall, 28 subjects were ventilated with NIV and 6 with CPAP (Table 2). A face mask was used in $97 \%$ of subjects, and $79 \%$ of ventilated subjects had OSA. Additional oxygen was used in 9 subjects (26\%). Subjects ventilated with NIV had the following average parameters: IPAP $23 \pm 2 \mathrm{~cm} \mathrm{H}_{2} \mathrm{O}$, expiratory positive airway pressure $7 \pm 2 \mathrm{~cm} \mathrm{H}_{2} \mathrm{O}$, and breathing frequency 16 breaths/min.

\section{Characteristics of Obese Subjects Receiving Home NIV}

After exclusion of the 4 subjects who underwent tracheotomy, the 3 who did not receive any ventilation during their hospital stay, and 1 subject who was already ventilated at home with good adherence, we analyzed 45 subjects. Ventilated subjects had a higher BMI than non-ventilated individuals ( $44 \pm 12$ vs $37 \pm 7$ $\mathrm{kg} / \mathrm{m}^{2}$, respectively, $\left.P=.01\right)$. IPAP used within the first $48 \mathrm{~h}$ of hospital stay was higher in subsequently ventilated subjects than in non-ventilated individuals at discharge $\left(22 \pm 2\right.$ vs $\left.21 \pm 2 \mathrm{~cm} \mathrm{H}_{2} \mathrm{O}, P=.040\right)$. Arterial blood gases at admission did not differ significantly between ventilated and non-ventilated subjects: $\mathrm{pH} 7.31 \pm 0.09$ versus $7.33 \pm 0.09, P=.56 ; \mathrm{P}_{\mathrm{aCO}_{2}}$ $62.3 \pm 17.4$ versus $65.5 \pm 21.0 \mathrm{~mm} \mathrm{Hg}, P=.65$ ). The cause of ARF was primarily idiopathic acute hypercapnic respiratory failure and was similar in both groups $(P=.17)$. Subjects who were already ventilated at home did not receive more invasive mechanical ventilation than other subjects $(P=.70)$.

\section{1-Year Follow-Up}

At 1 y, 7 of 53 subjects had been readmitted, with an average of 2 readmissions per subject; in addition, $36 \%$ of non-ventilated subjects were readmitted versus $33 \%$ of tracheostomized subjects and $10 \%$ of subjects with NIV at home $(P=.14)$. There was no difference for readmissions between subjects who were ventilated at home and those who were not ( $10 \%$ vs $36 \%, P=.07)$. Three subjects died within the year after hospitalization; 2 of these subjects were ventilated at home and one was not.

Among the 34 subjects who were ventilated at home, 14 were followed up at 6 months and 12 months. There was no follow-up available for subjects treated with CPAP at home. At 12 months, 4 subjects were no longer ventilated (mean duration of NIV was $6 \pm 4.2$ months), and 3 subjects died. Mean BMI at 12 months for the 14 individuals who were followed up was $43 \pm 10$ versus $45 \pm 12 \mathrm{~kg} / \mathrm{m}^{2}$ at baseline $(P=.038)$. In these subjects, bicarbonate levels and $\mathrm{P}_{\mathrm{aCO}_{2}}$ were also lower at 12 months compared with baseline $(26 \pm 3$ vs $27 \pm 3 \mathrm{mEq} / \mathrm{L}$ and $41.7 \pm 6.7$ vs $43.6 \pm 7.5 \mathrm{~mm} \mathrm{Hg}$, respectively, $P=.006$ and $P=.01$, respectively). Mean adherence at 1 month, 6 months, and 12 months was $5.7 \pm 2.9,7.0 \pm 3.1$, and $7.1 \pm 2.1 \mathrm{~h} / \mathrm{d}$, respectively, without any significant difference over time (Fig. 3). 


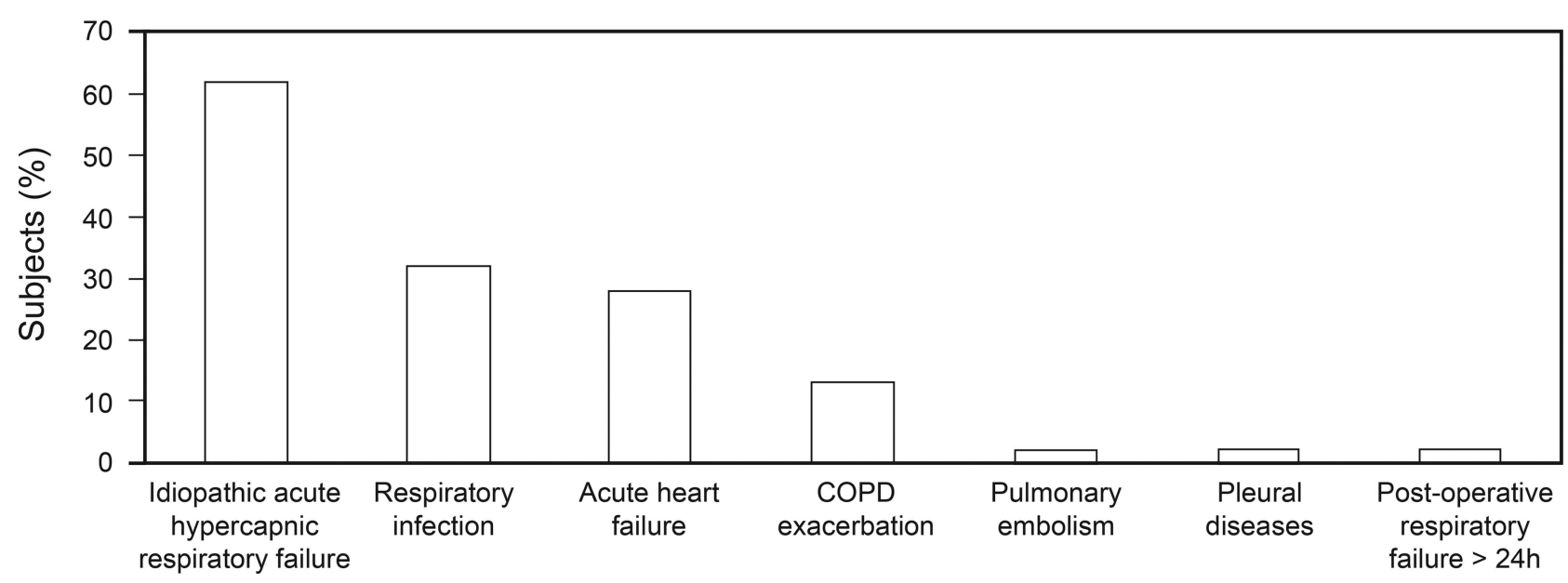

Fig. 2. Causes of acute respiratory failure in the study population.

Table 2. Ventilation Status of Obese Subjects at Discharge According to Their Ventilation Status Prior to Admission

\begin{tabular}{|c|c|c|c|c|c|}
\hline & \multicolumn{5}{|c|}{ Ever ventilated prior to admission, $n(\%)$} \\
\hline & No & BPAP & CPAP & Refused & Total \\
\hline \multicolumn{6}{|c|}{ Ventilation at discharge } \\
\hline None & $15(44)$ & $0(0)$ & $0(0)$ & $0(0)$ & $15(28)$ \\
\hline NIV & $14(41)$ & $8(100)$ & $4(44)$ & $2(100)$ & $28(53)$ \\
\hline CPAP & $2(6)$ & $0(0)$ & $4(44)$ & $0(0)$ & $6(11)$ \\
\hline Tracheostomy & $3(9)$ & $0(0)$ & $1(11)$ & $0(0)$ & $4(8)$ \\
\hline Total & $34(100)$ & $8(100)$ & $9(100)$ & $2(100)$ & $53(100)$ \\
\hline \multicolumn{6}{|c|}{$\begin{array}{l}\text { NIV = noninvasive ventilation } \\
\text { BPAP = bilateral positive airwa }\end{array}$} \\
\hline
\end{tabular}

\section{Parameters Associated With NIV Adherence At 6 Months}

At 6 months, 18 subjects $(86 \%)$ were adherent with NIV. Those who had been previously ventilated at home were not likely to be classified as being more adherent $(P=.93)$. Adherent subjects had also a longer duration of NIV at 1 month than non-adherent individuals at 6 months $(6.8 \pm 2.1$ vs $2.6 \pm 2.1 \mathrm{~h} / \mathrm{d} ; P=.02)$. Non-adherent subjects at 6 months had lower bicarbonate levels at admission and higher FVC than adherent subjects ( $24 \pm 5$ vs $34 \pm 8 \mathrm{mEq} / \mathrm{L}$ and $77 \pm 5$ vs $61 \pm 14 \%$ predicted value, respectively, $P=.040$ and $P=.040$, respectively). They were also ventilated at home with a lower breathing frequency (12 \pm 6 vs $16 \pm 0$ breaths/min, $P=.01)$. None of the non-adherent subjects at 6 months received invasive ventilation during hospitalization $(P=.99)$. Age, gender, medical history, and arterial blood gases at admission were not predictive factors of better adherence at 6 months in our population.

\section{Discussion}

In this retrospective analysis, we identified characteristics of obese adult subjects receiving long-term NIV after hospitalization in the ICU for ARF. Subjects subsequently ventilated with NIV at home had a higher BMI and a higher level of initial IPAP than those who did not receive NIV at discharge.

Higher BMI in subjects who had been ventilated with NIV at home after initial management in ICU was a strong indicator that clinicians were more disposed to propose long-term NIV when they estimated that subjects were at higher risk of chronic respiratory failure, as it is well known that prevalence of both OSA and obesity-hypoventilation syndrome increases with BMI. ${ }^{5}$ At admission, $62 \%$ of our subjects had alveolar hypoventilation. In fact, obesity-hypoventilation syndrome is defined as the association of obesity, chronic diurnal hypoxia and hypercapnia, possible sleep-related respiratory disorder, and exclusion of other causes of alveolar hypoventilation at baseline. 5,15 Unfortunately, all of our included subjects exhibited ARF, and 

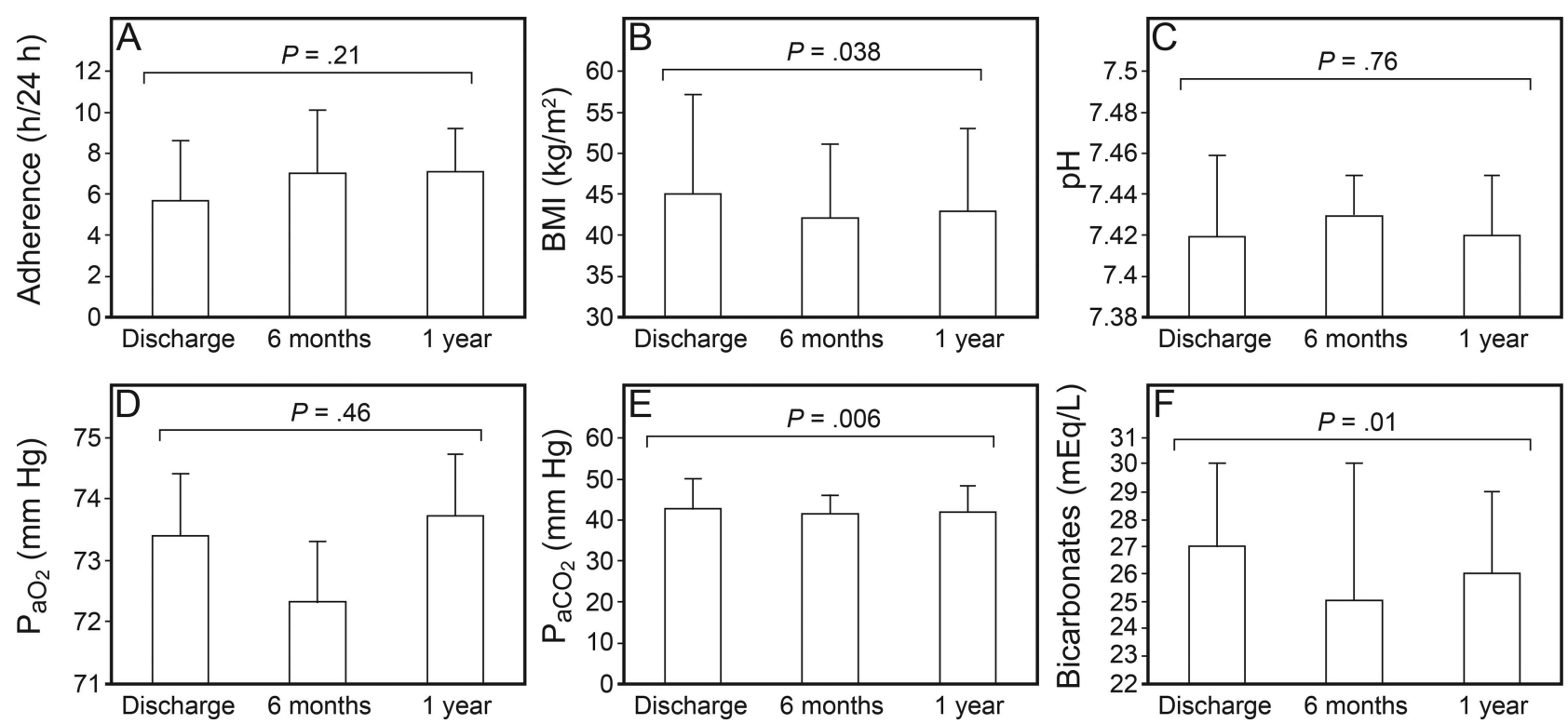

Fig. 3. Adherence, body mass index (BMI), and arterial blood gases at discharge and at 6 months and 1 year of noninvasive ventilation.

most of them did not have available arterial blood gases at baseline. Thus, we can only strongly speculate that most of them had obesity-hypoventilation syndrome. The same occurred for OSA, as respiratory polygraphy is not feasible during acute episodes of respiratory failure. Therefore, confirmation of OSA usually occurs after this initial event, unless it was already known prior to admission.

We did not reevaluate the indications for home NIV once the subjects stabilized because NIV would have to be stopped several weeks before performing both polygraphy and arterial blood gases. We considered that it would not have been ethical to do that after an initial ARF.

Higher levels of initial IPAP in subjects who had been ventilated with NIV at home after initial management in the ICU might be linked with higher BMI. Obese subjects have lower lung adherence ${ }^{16,17}$ and thus need a higher inspiratory pressure to generate an efficient respiratory volume. A higher BMI is linked with more difficulty breathing, which in turn is associated with a higher initial IPAP.

Our data support the efficacy of NIV in obese subjects presenting with acute hypercapnic respiratory failure, with only $10 \%$ of subjects failing the modality. Lemyze et al ${ }^{18}$ reported a failure rate of $17 \%$ in a cohort of more severely obese subjects (mean BMI $49.6 \mathrm{~kg} / \mathrm{m}^{2}$ ). Of interest, the initial level of IPAP was higher in our study than in the study by Lemyze et al, ${ }^{18}$ which may have contributed to this higher success rate. Although not used enough, NIV has demonstrated efficiency in the management of ARF in obese subjects, regardless of cause. ${ }^{19,20}$ This has to be compared with the well-known effects of NIV in subjects with COPD. In fact, guidelines recommend the use of NIV in COPD-associated acute hypercapnic respiratory failure, although the failure rate has been reported to vary from
$7 \%$ to $50 \% .{ }^{21}$ In a study comparing NIV efficacy in acute hypercapnic respiratory failure associated with obesity hypoventilation syndrome or COPD, Carillo et al ${ }^{22}$ reported better outcomes in obese subjects, including lower rates of late failure, lower intra-hospital mortality, and higher survival rate at $1 \mathrm{y}$. As in the study of Gursel et al, ${ }^{20} 41 \%$ of our subjects had an obstructive pattern and 34\% suffered from COPD. The prevalence of COPD is high in obese patients. In COPD subjects, obesity is associated with less late failure and readmission. ${ }^{22}$

Several studies have confirmed the benefits of NIV at home in obese subjects with OSA or obesity-hypoventilation syndrome, including reduced mortality, decreased readmission rate, reduced daytime sleepiness, and improved quality of life. ${ }^{11,23,24}$ In our study, the global readmission rate for ARF at $1 \mathrm{y}$ was $20 \%$, with a trend in favor of NIV at home (10\% readmissions) compared with no ventilation at home (36\% readmissions, including 3 of 4 subjects who refused long-term NIV) $(P=.07)$. We speculate that the relatively low number of subjects affected the generalizability of these results. In a larger retrospective study of 280 subjects who were ventilated for hypercapnic respiratory failure, including 71 with obesity-hypoventilation syndrome, Janssens et $\mathrm{al}^{9}$ reported a significant decrease in the number of days spent at hospital during the years after ventilation when compared to the year preceding ventilation.

In our study, we reported significant improvement in alveolar hypoventilation at 6 months and 12 months after NIV initiation. Budweiser et $\mathrm{al}^{24}$ have also reported significant improvement in arterial blood gases, pulmonary function tests, and BMI at 6 months. We should mention that improvement in arterial blood gases was relatively 
less pronounced in our cohort, probably because we took results at discharge as the reference point for further comparisons, despite the fact that NIV had been already initiated at that time. The reduction in BMI at 6 months and 12 months is also of interest in such obese individuals. Priou et al notably found a good correlation between BMI and $\mathrm{P}_{\mathrm{aCO}}$ at 6 months. ${ }^{23}$ Thus, the benefits of NIV in obese patients occur not only during ARF, but also after several months.

Removal of NIV at $1 \mathrm{y}$ was observed in $18 \%$ of our subjects and occurred 6 months after discharge. The only reason for this removal was persistent poor adherence. We noticed that adherence at 1 month was already poor in these 4 subjects, with a mean duration of use $<2$ hours per day. By contrast, overall adherence was good, reaching an average of $7.1 \pm 2.1 \mathrm{~h} / \mathrm{d}$ at $1 \mathrm{y}$, with $83 \%$ of subjects using their machine more than $5 \mathrm{~h} / \mathrm{d}$. These data are in accordance with those of Priou et al, ${ }^{23}$ although follow-up period was shorter in our population.

We observed that adherence at 1 month was predictive of long-term use of the ventilator at home. In our population, poor adherence after only 1 month of NIV at home was a strong indicator of subsequent NIV removal. After discharge, it is not uncommon to reevaluate subjects after only 3 months. On the basis of our data, we propose reevaluation of obese patients who started NIV at 1 month after discharge from ICU: the earlier they can be managed, the better their adherence will be. Personalized therapeutic education, reassurance, and control of both mask and machine should be delivered early after discharge to help improve acceptance of long-term NIV in obese patients.

Among other parameters associated with poor NIV adherence, higher FVC, lower bicarbonate level at admission, and lower breathing frequency were identified in this study. Such criteria might reflect a lower severity, as McArdle et $\mathrm{al}^{25}$ have shown that subjects with moderate OSA were less adherent than those with severe OSA. One could argue that these subjects might also have been overtreated with NIV despite the possible lack of clear medical indication for long-term ventilation. This remains to be determined in larger cohorts.

Our study has some limitations. It is a retrospective study, with a limited number of subjects, some of whom were lost to follow-up. However, our data were in accordance with larger cohorts who followed subjects for $>1 \mathrm{y}$. Moreover, data from our specialized center cannot be generalized to less experienced units. Finally, all subjects were given NIV during an acute episode of respiratory failure; their respiratory status at baseline was not always known, which made it difficult to classify all subjects in the OSA, obesity-hypoventilation syndrome, and overlapping syndrome categories.

\section{Conclusion}

After admission to the ICU for ARF, $64 \%$ of our obese subjects were put on NIV at home. These subjects had more severe obesity and were more difficult to ventilate during the initial episode. However, our study confirmed the benefit of NIV in obese subjects. Long-term NIV was also associated with improvements in BMI and arterial blood gases at $1 \mathrm{y}$. It is important to mention that NIV has some constraints and can be difficult for patients to fully accept, especially when their symptoms are not too severe. In our study, poor adherence at 1 month was associated with poor adherence at 6 months. Therefore, early evaluation of obese patients who are discharged from the ICU with NIV at home could be helpful to improve long-term management after ARF.

\section{REFERENCES}

1. World Health Organization. (n.d.). Obésité: prevention et prise en charge de l'épidémie mondiale. Available: http://whqlibdoc.who.int/ trs/WHO_TRS_894_fre.pdf

2. Roche. Obepi_2012.pdf. (n.d.). Available: http://www.roche.fr/content/ dam/corporate/roche_fr/obepi_2012.pdf

3. Luce JM. Respiratory complications of obesity. Chest 1980;78(4): 626-631.

4. O'Donnell CP, Tankersley CG, Polotsky VP, Schwartz AR, Smith PL. Leptin, obesity, and respiratory function. Respir Physiol 119(23):163-170, 2000.

5. Mokhlesi B. Obesity hypoventilation syndrome: a state-of-the-art review. Respir Care 2010;55(10):1347-1362-1365.

6. Schäfer H, Ewig S, Hasper E, Lüderitz B. Failure of CPAP therapy in obstructive sleep apnoea syndrome: predictive factors and treatment with bilevel-positive airway pressure. Respir Med 1998;92(2): 208-215.

7. Rapoport DM, Garay SM, Epstein H, Goldring RM. Hypercapnia in the obstructive sleep apnea syndrome. A reevaluation of the "Pickwickian syndrome." Chest 1986;89(5):627-635

8. Piper AJ, Wang D, Yee BJ, Barnes DJ, Grunstein RR. Randomised trial of CPAP vs bilevel support in the treatment of obesity hypoventilation syndrome without severe nocturnal desaturation. Thorax 2008; 63(5):395-401.

9. Janssens J-P, Derivaz S, Breitenstein E, De Muralt B, Fitting J-W, Chevrolet J-C, Rochat T. Changing patterns in long-term noninvasive ventilation: a 7 -year prospective study in the Geneva Lake area. Chest 2003;123(1):67-79.

10. Laub M, Midgren B. Survival of patients on home mechanical ventilation: a nationwide prospective study. Respir Med 2007;101(6): 1074-1078.

11. Masa JF, Celli BR, Riesco JA, Hernández M, Sánchez De Cos J, Disdier C. The obesity hypoventilation syndrome can be treated with noninvasive mechanical ventilation. Chest 2001;119(4):1102-1107.

12. Cheng S-L, Chan VL, Chu C-M. Compliance with home non-invasive ventilation. Respirology. 2012;17(4):735-736.

13. Díaz GG, Alcaraz AC, Talavera JCP, Pérez PJ, Rodriguez AE, Cordoba FG, Hill NS. Noninvasive positive-pressure ventilation to treat hypercapnic coma secondary to respiratory failure. Chest 2005; 127(3):952-960.

14. Ferrer M, Esquinas A, Leon M, Gonzalez G, Alarcon A, Torres A. Noninvasive ventilation in severe hypoxemic respiratory failure: a 
randomized clinical trial. Am J Respir Crit Care Med 2003;168(12): 1438-1444.

15. Piper AJ, Grunstein RR. Obesity hypoventilation syndrome: mechanisms and management. Am J Respir Crit Care Med 2011;183(3):292-298.

16. Salome CM, King GG, Berend N. Physiology of obesity and effects on lung function. J Appl Physiol 2010;108(1):206-211.

17. Parameswaran K, Todd DC, Soth M. Altered respiratory physiology in obesity. Can Respir J 2006;13(4):203-210.

18. Lemyze M, Taufour P, Duhamel A, Temime J, Nigeon O, Vangrunderbeeck N, et al. Determinants of noninvasive ventilation success or failure in morbidly obese patients in acute respiratory failure. PloS One 2014;9(5):e97563.

19. Rabec C, Merati M, Baudouin N, Foucher P, Ulukavac T, ReybetDegat $\mathrm{O}$. [Management of obesity and respiratory insufficiency. The value of dual-level pressure nasal ventilation.] Rev Mal Respir. 15(3): 269-278, 1998.

20. Gursel G, Aydogdu M, Gulbas G, Ozkaya S, Tasyurek S, Yildirim F. The influence of severe obesity on non-invasive ventilation (NIV) strategies and responses in patients with acute hypercapnic respiratory failure attacks in the ICU. Minerva Anestesiol 2011;77(1):17-25.
21. Lightowler JV, Elliott MW. Predicting the outcome from NIV for acute exacerbations of COPD. Thorax 2000;55(10):815-816.

22. Carrillo A, Ferrer M, Gonzalez-Diaz G, Lopez-Martinez A, Llamas $\mathrm{N}$, Alcazar M, et al. Noninvasive ventilation in acute hypercapnic respiratory failure caused by obesity hypoventilation syndrome and chronic obstructive pulmonary disease. Am J Respir Crit Care Med 2012;186(12):1279-1285.

23. Priou P, Hamel J-F, Person C, Meslier N, Racineux J-L, Urban T, Gagnadoux F. Long-term outcome of noninvasive positive pressure ventilation for obesity hypoventilation syndrome. Chest 2010;138(1): 84-90.

24. Budweiser S, Riedl SG, Jörres RA, Heinemann F, Pfeifer M. Mortality and prognostic factors in patients with obesity-hypoventilation syndrome undergoing noninvasive ventilation. J Intern Med 2007; 261(4):375-383.

25. McArdle N, Devereux G, Heidarnejad H, Engleman HM, Mackay TW, Douglas NJ. Long-term use of CPAP therapy for sleep apnea/ hypopnea syndrome. Am J Respir Crit Care Med 1999;159(4 Pt 1): 1108-1114.

This article is approved for Continuing Respiratory Care Education credit. For information and to obtain your CRCE

(free to AARC members) visit

www.rcjournal.com 